\title{
The importance of cooling of urine samples for doping analysis
}

\author{
J. Gijs Kuenen • Wil N. Konings
}

Received: 30 July 2009/ Accepted: 6 October 2009/Published online: 25 October 2009

(c) The Author(s) 2009. This article is published with open access at Springerlink.com

\begin{abstract}
Storing and transporting of urine samples for doping analysis, as performed by the anti-doping organizations associated with the World Anti-Doping Agency, does not include a specific protocol for cooled transport from the place of urine sampling to the doping laboratory, although low cost cooling facilities can easily be made available. As a result, microbial and thermal degradation of the chemical substances in the urine may occur, which may lead to false negative or false positive results in the subsequent doping analysis. This scientifically and morally unacceptable practice is still maintained in spite of publications demonstrating that immediate cooling is an absolute requirement. Given the enormous societal consequences of positive tests, the lack of a controllable chain of custody during transport should be outlawed. This paper proposes a simple method, based on immediate cooling and cooled transport, which can easily be implemented in developed countries at low cost.
\end{abstract}

Keywords Urine analysis - Bacterial contamination . Doping analysis $\cdot$ Anti-doping organization

Papers published in this section do not necessarily reflect the opinion of the Editors, the Editorial Board and the Publisher.

J. G. Kuenen $(\bowtie)$

Department of Biotechnology, Delft University of Technology, Julianalaan 67, 2628 BC Delft, The Netherlands

e-mail: j.g.kuenen@tudelft.nl

W. N. Konings

Department of Microbiology, University of Groningen, Kerklaan 30, 9751 NN Haren, The Netherlands

\section{Introduction}

Given the importance for the athlete of a correctly performed doping analysis of his urine, anti-doping institutions and laboratories carry the scientific and moral obligation of applying the highest quality of work standards to make sure that the results of the analysis are a correct representation of the composition of the urine at the moment that it was taken from the athlete's body. Anti-doping laboratories work under a strict set of quality rules approved by the World AntiDoping Agency (WADA). However, WADA has not provided the national anti-doping organizations (ADO) with a strict protocol on how to handle the urine samples during storage and transport from the doping control station (i.e., the sampling site of the urine) to the doping laboratory, although this forms an important part of the total chain of custody (chronological documentation of the handling of the urine) [1]. The WADA has given the responsibility for this part of the chain to the national ADO. The WADA requirement for the protocol developed and authorized by ADO is that identity, integrity and safety of the urine sample must be guaranteed.

This discussion focuses on the microbiological aspects of sampling, storage and transport of urine samples from the doping collection station (International Standard for Testing [1]) until the opening for analysis of the samples in the doping laboratory, where other guidelines apply (International Standard for Laboratories) [2]. This paper does not discuss the problems of thermal degradation, which also can occur with certain components present in urine samples [3, 4].

\section{Urine as a rich source for microbial growth}

The composition of human urine is very complex and influenced by the food taken prior to sampling. In all cases, 
urine represents a rich nutrient source for the growth of microorganisms. At a temperature between 5 and $40{ }^{\circ} \mathrm{C}$ and a modest $\mathrm{pH}$ (4.5-8.5) microorganisms can multiply at very high rates with generation times as low as $30 \mathrm{~min}$. [5-7] As a result, a single bacterium can increase to $10^{9}$ cells in $15 \mathrm{~h}$.

In principle, urine in the bladder is sterile. It gets, however, contaminated with bacteria when it leaves the urinal tract and is collected in bottles, which are not sterilized. Initial contaminations can be in the order of $10^{4}$ cells $/ \mathrm{ml}$ and hence it would take less than $10 \mathrm{~h}$ to reach $10^{9}$ cells $/ \mathrm{ml}$ and thus spoil the urine sample completely.

Laboratory experiments, using urine samples from a number of individuals incubated at $20-30{ }^{\circ} \mathrm{C}$, have proven that the described storage circumstances lead to significant microbial contamination. In each of the samples, substantial contamination, i.e., spoiling of the sample, was demonstrated within 16-24 h, as shown by visual and microscopic inspection ([6, 7] and experiments performed by one of the authors). In these cases also the $\mathrm{pH}$ had risen.

It must be stressed that a large diversity of microorganisms, bacteria, yeast and fungi can grow in urine. They posses an even much larger array of biological systems, including enzymes that can change the compounds present in the urine $[4,8]$. A large number of publications have shown that specific enzymes can transform a multitude of hormones, drugs, antibiotics and xenobiotics [4]. In essence, it is close to impossible to predict exactly the outcome of microbial degradation, transformation and even new synthesis of complex compounds, such as steroids [8, 9]. This can lead to false-negative and even false-positive doping tests [9]. Therefore, it is obvious that microbial contaminated samples no longer represent the originally sampled urine and hence had lost their integrity. They are therefore not suitable anymore for further analysis. Indeed, it is unthinkable that any medical laboratory would ever accept contaminated urine samples for analysis.

The inescapable conclusion is that to maintain the integrity of urine samples, microbial growth should be inhibited. A recent literature study, financed by WADA, by Tsivou et al. [4] gives an excellent overview of different options. The conclusion of that study is that no other method other than cooling and storing at $\leq 5{ }^{\circ} \mathrm{C}$ is suitable. However, to our great surprise, it is accepted as a matter of fact in the same report that cooling or freezing during transport is not always possible in the daily practice of doping control. We challenge this fact as totally out of date and therefore scientifically and morally unacceptable (Table 1).

Table 1 The sampling, storage and transport of urine samples for doping control

\begin{tabular}{|c|c|}
\hline Existing method & Recommended method \\
\hline $\begin{array}{l}\text { 1. Collect a minimum of } 100 \mathrm{ml} \text { of urine at the doping } \\
\text { control station }\end{array}$ & $\begin{array}{l}\text { 1. Collect a minimum of } 100 \mathrm{ml} \text { of urine at the doping } \\
\text { control station }\end{array}$ \\
\hline 2. Distribute $2 / 3$ in bottle $A$ and $1 / 3$ in bottle $B$ & 2. Distribute $2 / 3$ in bottle $A$ and $1 / 3$ in bottle $B$ \\
\hline \multirow[t]{2}{*}{ 3. Place in polystyrene insulating box ${ }^{a}$} & 3A. Cool down in crushed ice to $\leq 5^{\circ} \mathrm{C}$ \\
\hline & $\begin{array}{l}\text { 3B. After cooling, place in polystyrene insulating box } \\
\text { and transfer to (portable) electrically powered cooler, } \\
\text { maintained at } \leq 5^{\circ} \mathrm{C}\end{array}$ \\
\hline $\begin{array}{l}\text { 4. Transport to home of DCO. Cooling is not } \\
\text { performed }^{\mathrm{a}}\end{array}$ & $\begin{array}{l}\text { 4. Transport in powered cooler at } \leq 5^{\circ} \mathrm{C} \text { to home of } \\
\text { DCO }\end{array}$ \\
\hline 5. Place box in refrigerator of $\mathrm{DCO}$ at $\leq 5^{\circ} \mathrm{C}$ & $\begin{array}{l}\text { 5. Place box in refrigerator at } \leq 5{ }^{\circ} \mathrm{C} \text { or keep in cooler } \\
\leq 5{ }^{\circ} \mathrm{C}\end{array}$ \\
\hline $\begin{array}{l}\text { 6. Transport box from DCO to ADO collection point; } \\
\text { cooling not performed }^{\mathrm{a}}\end{array}$ & $\begin{array}{l}\text { 6. Transport box from DCO to ADO collection point, at } \\
\leq 5^{\circ} \mathrm{C} \text {, either in a cooler or in a refrigerated car }\end{array}$ \\
\hline 7. Store at ADO facilities. Cooling conditions unknown & 7. Store at ADO facilities at $\leq 5{ }^{\circ} \mathrm{C}$ \\
\hline $\begin{array}{l}\text { 8. Transport of combined samples from ADO to doping } \\
\text { laboratory in a truck. No cooling performed }\end{array}$ & $\begin{array}{l}\text { 8. Transport of combined samples from } \mathrm{ADO} \text { to doping } \\
\text { laboratory at } \leq 5{ }^{\circ} \mathrm{C} \text { in a refrigerated truck }\end{array}$ \\
\hline $\begin{array}{l}\text { 9. Receive in doping laboratory A-sample stored at } \\
\leq 5{ }^{\circ} \mathrm{C} \text { and B-sample frozen at }-20{ }^{\circ} \mathrm{C}\end{array}$ & $\begin{array}{l}\text { 9. Receive in doping laboratory A-sample stored at } \\
\leq 5{ }^{\circ} \mathrm{C} \text { and B-sample frozen at }-20{ }^{\circ} \mathrm{C}\end{array}$ \\
\hline 10. Analysis of sample A & 10. Analysis at $\leq 5$ days of total storage at $\leq 5{ }^{\circ} \mathrm{C}$ \\
\hline
\end{tabular}

The information mentioned on the existing method was obtained from different athletes and from written information on the management of the Dutch Anti-Doping Organization (ADO), which has stated that this method is representative for the majority of the World Anti-Doping Agency (WADA) associated countries. Samples are taken by the drug control officer (DCO)

${ }^{a}$ The items are microbiologically unacceptable, since uncontrolled growth of unknown micro-organisms can occur and hence the integrity of the sample can no longer be guaranteed 


\section{The current practice of sampling}

The current practice of sampling is summarized in first column of Table 1. The steps in the first column indicated by superscript a are microbiologically unacceptable, since uncontrolled growth of unknown microorganisms may occur. Hence the integrity of the sample can no longer be guaranteed.

Especially the fact that the samples are not cooled before placing in the polystyrene box (item 3) will result in a long period of storing at temperatures favorable for microbial growth, due to the high insulating capacity of the polystyrene box itself. In addition, the time between leaving the doping control station and the arrival at the home of the drug control officer (DCO) is not standardized. If the DCO has to visit and control different athletes, then this time can go up to between 10 and $15 \mathrm{~h}$. In the existing procedure, the samples will be held at conditions very favorable for microbial growth (item 4). In many countries/ laboratories, it is forbidden to put samples and food in the same refrigerator. The ADO can supply the DCO with a lockable refrigerator, which can also produce crushed ice. This is not done at this moment (item 5). The conclusion is that due to the lack of standardization in time and storage temperature, the existing procedure [1] is not in agreement with the principles of "chain of custody".

\section{Cooling and transport of urine is easy to realize}

Table 1 formulates in the second column a proposal of how cooling and cooled transport may be realized in practice.

In any developed country, cooling of food is standard and bound to strict rules. A complete transport infrastructure is available for cooled transport of small and big volumes. For the individual traveler, electrical coolers are available at low cost. Crushed ice can be obtained easily and hence direct cooling of small urine samples and transport at $\leq 5{ }^{\circ} \mathrm{C}$ is practicable at low cost. It can be calculated that to cool $100 \mathrm{ml}$ urine from 35 to $5{ }^{\circ} \mathrm{C}$, about $40 \mathrm{~g}$ of ice is necessary. This means that $100 \mathrm{~g}$ of ice is largely sufficient to cool the two samples.

Based on the experiences for storage of perishable food, we advise that the total storage time (item 4-9) must not be longer than 5 days (to be validated). If it is not possible to do the analysis within this period, the A-sample must be frozen until analysis.

Commercial manufacturers offer coolers with temperature indications and systems in which the alarms are activated when the temperature of the box rises. A future development can be to use temperature chips, which record the temperature as a function of time and can be read after opening the samples in the laboratory. This would be completely in accordance with the principles of the "chain of custody".

\section{Control of microbial growth}

It is of utmost importance that urine samples are checked for microbial growth when they are opened in the laboratory. Often, this is only done by visual inspection of the sample, which is inaccurate and subjective. In microbiology, a number of methods are available and in use, for example based on turbidity, and a variety of highly sensitive staining techniques with particle counting, which can easily be implemented in the laboratory. Standard microscopy of stained samples can easily detect the growth of microorganisms at a level that is at least 100 times more sensitive than by direct visual inspection, whilst the sensitivity can easily be further increased by filtering.

\section{Validation}

In the existing method, the temperatures and the storage and transport times of the samples are not recorded, and especially not standardized. Therefore, in the current method/practice, every basis for validation and authorization as required by WADA is lacking,

If the newly proposed method is followed, validation would be straightforward, because the urine sample would be maintained at a temperature of $\leq 5{ }^{\circ} \mathrm{C}$ for a maximum of 5 days. For validation, a large number of fresh urine samples can be monitored for growth and/or activity of microorganisms at this temperature as a function of time. The period, during which the number of microorganisms did not increase in number significantly, would set the maximum storage time of the samples from a microbiological point of view. We realize that other (bio)chemical considerations and data may reduce the acceptable time even further. If it is not possible to do the analysis within the validated period, the A-sample must be frozen until analysis. The proposed method is well in accordance with good laboratory practice [10], whilst the existing method is not.

Open Access This article is distributed under the terms of the Creative Commons Attribution Noncommercial License which permits any noncommercial use, distribution, and reproduction in any medium, provided the original author(s) and source are credited.

\section{References}

1. WADA: International Standard for Testing. http://www.wadaama.org/rtecontent/document/IST_En_2009.pdf 
2. WADA: International Standard for Laboratories. http://www. wada-ama.org/rtecontent/document/International_Standard_for_ Laboratories_v6 January_2009.pdf

3. Van Eenoo P, Lootens L, Spaerkeer A, Van Tuyne W, Deventer K, Delbeke FT (2007) Results of stability studies with doping agents in urine. J Anal Toxicol 31:543-548

4. Tsivou M, Livadara D, Georgakopoulos DG, Koupparis MA J, Atta-Politou J, Georgakopoulos CG (2009) Stabilization of human urine doping control samples. Anal Biochem 388:179-191

5. Hartley HJ (2004) "An innocent abroad": the Diane Modahl doping case 1994-2001. Int Sports Law J 3-4:61-65

6. Asscher AW, Sussman M, Waters WE, Harvard Davis R, Chick S (1966) Urine as a medium for bacterial growth. Lancet 7472:1037-1041

7. Gordon DM, Riley MA (1992) A theoretical and experimental analysis of bacterial growth in the bladder. Mol Microbiol 6:555-562
8. De la Torre R, De la Torre X, Alıa C, Segura J, Baro T, Torres-Rodriguez JM (2001) Changes in androgenic steroid profile due to urine contamination by microorganisms: a prospective study in the context of doping control. Anal Biochem 289:116-123

9. Kicman AT, Fallon JK, Cowan DA, Walker C, Easmon S, Mackintosh D (2002) Candida albicans in urine can produce testosterone: impact on the testosterone/epitestosterone sports drug test. Clin Chem 48:1799-1801

10. OECD Environmental Health and Safety Publications, Series on Principles of Good Laboratory Practice and Compliance Monitoring. No. 1. OECD Principles of Good Laboratory Practice (as revised in 1997), Environment Directorate 